\title{
In-vitro activity of roxithromycin against respiratory and skin pathogens
}

\author{
J.-C. Pechère and R. Auckenthaler \\ Département de Microbiologie, CMU, 9, Avenue de Champel, 1211 Genève 4, \\ Switzerland
}

\begin{abstract}
The activity of roxithromycin was determined by a microdilution method, in comparison with erythromycin, spiramycin and josamycin. Roxithromycin and erythromycin showed very similar MICs against staphylococci, Streptococcus pneumoniae, Str. pyogenes and Haemophilus influenzae. In most cases, spiramycin and josamycin appeared similarly or more active. The activity of roxithromycin against Mycoplasma pneumoniae, Legionella spp., Chlamydia psittaci and, to some extent, against Pasteurella spp. was also assessed, by suitable in-vitro methods. Roxithromycin has a promising potential for treating selected skin and respiratory infections.
\end{abstract}

\section{Introduction}

Erythromycin is a macrolide antibiotic which is useful for therapy of respiratory and skin infections caused by susceptible micro-organisms such as Staphylococcus, Streptococcus, Mycoplasma, Chlamydia and Legionella spp. Roxithromycin is a new ethero oxime derivative of erythromycin (Jones, Barry \& Thornsberry, 1983) with improved pharmacokinetic properties. This report compares the in-vitro activity of roxithromycin, erythromycin, josamycin, and spiramycin against different microorganisms causing skin or respiratory infections.

\section{Materiaks and methods}

\section{Personal studies}

A total of 247 bacterial isolates were collected by the Laboratoire Central de Bactériologie or, occasionally, in other Swiss hospitals. These isolates included 56 Staph. aureus, 26 Staph. epidermidis, 24 Staph. saprophyticus, 62 Str. pneumoniae, 38 Str. pyogenes, 20 Haemophilus influenzae and 21 Nocardia asteroides. The above bacteria were typical strains, according to conventional identification methods. They were kept frozen in skim milk at $-70^{\circ} \mathrm{C}$. Before study, organisms were thawed, streaked on to sheep blood agar and incubated overnight at $35^{\circ} \mathrm{C}$. Standard antibiotic powders were obtained from their respective manufacturers. Antibiotic working solutions were prepared according to the instructions of the manufacturer and used immediately after appropriate dilution in water or in broth.

Antimicrobial activity was measured in most cases by a microdilution method in Mueller-Hinton broth, following the M7-T procedure specified by the National 
Committee for Clinical Laboratory Standards (1983). The final inoculum of $10^{5}-10^{6} \mathrm{cfu} / \mathrm{ml}$ was prepared from a trypticase soy broth inoculated $4 \mathrm{~h}$ before and controlled by viable counts. The inoculum for $H$. influenzae was prepared and tested in Brain Heart Infusion broth supplemented with 5\% nicotinamide diphosphate and $10 \%$ haemin. For all strains, except $N$. asteroides, the MIC was read after $18 \mathrm{~h}$ of incubation at $35^{\circ} \mathrm{C} . N$. asteroides was tested by agar dilution on Mueller-Hinton agar with $10^{4} \mathrm{cfu} / \mathrm{spot}$ with $35^{\circ} \mathrm{C}$ incubation for three days. In all cases, the MIC was defined as the lowest antibiotic concentration yielding no growth visible to the naked eye.

\section{Other studies}

For completion of this study, and after permission from their respective authors, some reports prepared for Roussel Uclaf, Paris, are quoted here. These reports and their methods follow. C. Bebear (Hôpital Pellegrin Bordeaux, France) studied ten strains of $M$. pneumoniae, and determined the MIC of macrolides in agar dilution (Hayflick medium, pH 7.2, containing $20 \%$ of foal serum). K. Suzaki and Y. Niitu (The Research Institute for Tuberculosis and Cancer, Tohoku University, Japan) tested the growth inhibitory effect of roxithromycin on $M$. pneumoniae by a microdilution method using a standard mycoplasma broth ( $\mathrm{pH}$ 7.6) without penicillin but with phenol red. J. Fleurette determined the MIC of roxithromycin for 98 strains of Legionella spp. (30 reference strains from the CDC, Atlanta, Georgia, U.S.A., representative of 15 different species and various serotypes; 34 strains of clinical origin; 34 strains from the environment). This study was carried out by using the antibiotic medium No. 1 (Oxoid), supplemented with iron pyrophosphate $(0.25 \mathrm{~g} / \mathrm{l})$ and L-cystein hydrochloride $(0.4 \mathrm{~g} / \mathrm{l})$. Three other reports, respectively by I. D. Farrell (Public Health Laboratory service, East Birmingham Hospital, England), A. Buré (Hôpital Claude Bernard, Paris, France) and J. Acar (Hôpital Saint Joseph, Paris, France) also dealt with Legionella spp., but used BCYE medium (broth or agar). J. Orfila (C.H.U., Amiens, France) studied growth inhibition of $C$. psittaci by macrolides and tetracyclines in a cell line (HELA 229). R. C. Spencer, Royal Hallamshire Hospital, Sheffield, England, determined the activity of roxithromycin against 10 strains of Pasteurella spp. isolated from skin infections.

\section{Results and discussion}

Staph. aureus

The collection of Staph. aureus was divided into three categories according to the activity of benzyl-penicillin and oxacillin (Table I). Roxithromycin appeared active $\left(\mathrm{MIC}_{100} 2 \mathrm{mg} / \mathrm{l}\right)$ against the strains that were susceptible to these two $\beta$-lactam compounds, confirming previous studies (Jones, Barry \& Thornsberry, 1983; Rolston, Le Blanc \& Ho, 1986). Roxithromycin was also active against all strains that were resistant to benzylpenicillin (MIC $>32 \mathrm{mg} /$ ) and susceptible to oxacillin. Generally, in this collection, the activity of roxithromycin was comparable with that of erythromycin within one dilution, with the exception of three strains for which the MIC of erythromycin was four to eight times higher than that of roxithromycin. Spiramycin and josamycin appeared to be slightly more active than erythromycin and 
Table 1. Activity of macrolides against skin and respiratory pathogens (personal data)

\begin{tabular}{|c|c|c|c|c|}
\hline $\begin{array}{l}\text { Organisms } \\
\text { (number) }\end{array}$ & Antibiotic & $\begin{array}{l}\mathrm{MIC}_{s 0} \\
(\mathrm{mg} / \mathrm{l})\end{array}$ & $\begin{array}{l}\mathrm{MIC}_{90} \\
(\mathrm{mg} / \mathrm{I})\end{array}$ & $\begin{array}{l}\text { Range } \\
(\mathrm{mg} / \mathrm{l})\end{array}$ \\
\hline Penicillin-sensitive & roxithromycin & 1 & 2 & $0.5-2$ \\
\hline \multirow[t]{3}{*}{ Staph. aureus (18) } & erythromycin & 2 & 4 & $1-16$ \\
\hline & spiramycin & 0.5 & 1 & $0.25-1$ \\
\hline & josamycin & 0.25 & 1 & $0.25-0.5$ \\
\hline Penicillin-resistant & roxitbromycin & 2 & 2 & $1-2$ \\
\hline oxacillin-sensitive & erythromycin & 4 & 4 & $2-4$ \\
\hline \multirow[t]{2}{*}{ Staph. aureus (18) } & spiramycin & 1 & 1 & $0 \cdot 5-1$ \\
\hline & josamycin & 0.25 & 0.5 & $0.25-0.5$ \\
\hline Oxacillin-resistant & roxithromycin & 128 & 128 & $1->128$ \\
\hline \multirow[t]{3}{*}{ Staph. aureus (20) } & erythromycin & 128 & 128 & $2->128$ \\
\hline & spiramycin & 1 & 128 & $0.5->128$ \\
\hline & josamycin & 0.5 & 128 & $0.25->128$ \\
\hline \multirow[t]{4}{*}{ Staph. epidermidis (26) } & roxithromycin & 0.5 & 128 & $0.25-128$ \\
\hline & erythromycin & 1 & 128 & $0.06-128$ \\
\hline & spiramycin & 0.25 & $0 \cdot 25$ & $0.06-128$ \\
\hline & josamycin & 0.25 & $0 \cdot 25$ & $0 \cdot 125-128$ \\
\hline \multirow[t]{4}{*}{ Staph. saprophyticus (24) } & roxithromycin & 0.5 & 32 & $0 \cdot 25-32$ \\
\hline & erythromycin & 1 & 16 & $0 \cdot 5-64$ \\
\hline & spiramycin & 0.25 & 0.5 & $0 \cdot 125-1$ \\
\hline & josamycin & 0.5 & 2 & $0.25-2$ \\
\hline \multirow[t]{4}{*}{ Str. pneumoniae (62) } & roxithromycin & 0.4 & 0.4 & $0.025-12.8$ \\
\hline & erythromycin & 0.8 & 1.6 & $0 \cdot 1-6 \cdot 4$ \\
\hline & spiramycin & $0 \cdot 2$ & 0.8 & $0.012-3.2$ \\
\hline & josamycin & 0.1 & 0.2 & $0.025-0.4$ \\
\hline \multirow[t]{4}{*}{ Str. pyogenes (38) } & roxithromycin & 0.25 & 0.25 & $0.06-0.25$ \\
\hline & erythromycin & 0.25 & 0.5 & $0.125-0.5$ \\
\hline & spiramycin & 0.06 & 0.06 & $0.06-0.06$ \\
\hline & josamycin & $0 \cdot 125$ & $0 \cdot 125$ & $0.06-0.125$ \\
\hline \multirow{4}{*}{$H$. influenzae (20) } & roxithromycin & 8 & 8 & $1-8$ \\
\hline & erythromycin & 8 & 8 & $1-8$ \\
\hline & spiramycin & 8 & 8 & $2-8$ \\
\hline & josamycin & 8 & 8 & $2-16$ \\
\hline$N$. asteroides (21) & roxithromycin & 128 & 128 & $0.25->128$ \\
\hline
\end{tabular}

roxithromycin. The phenotype of resistance was strikingly different when we dealt with the oxacillin resistant strains (MIC $>32 \mathrm{mg} / \mathrm{l}$ ). Eighteen of the 20 oxacillin resistant strains were also resistant to erythromycin and roxithromycin. The general trend towards higher macrolide MICs among the oxacillin-resistant Staph. aureus is a known fact (Lyon \& Skurray, 1987), already observed with roxithromycin (Jones et al., 1983; Rolston et al., 1986). As an exception, two oxacillin resistant Staph. aureus were susceptible to the four macrolides tested. Besides, ten of 20 oxacillin resistant Staph. aureus demonstrated a so called dissociated phenotype of resistance, according to the terminology initially proposed by Garrod (1957): they were resistant to erythromycin, but sensitive to spiramycin and josamycin. Strains exhibiting the dissociated phenotype are now known to be inducibly resistant to all the $\mathrm{MLS}_{\mathrm{B}}$ (Macrolides, Lincosamides, Streptogramin type B) group of antibiotics via a methylation mediated by small multicopy plasmids (Weisblum, 1985). Our study shows that roxithromycin behaves as erythromycin and not as the two other macrolides in this respect. 


\section{Coagulase-negative staphylococci}

Among the 26 strains of Staph. epidermidis tested, 19 were susceptible (MIC $<2 \mathrm{mg} /$ ) to the four macrolides tested, five expressed the dissociated phenotype, and two exhibited generalized (Garrod, 1957) resistance. On a weight basis, activity of erythromycin and roxithromycin were comparable within one dilution, while spiramycin and josamycin were two to eight times more potent. As reported by Jones et al. (1983), no significant differences were found in the MICs for the Staph. epidermidis, whether or not they produced penicillinase. As to Staph. saprophyticus, 20 of 24 strains were susceptible to the four macrolides, whereas four strains showed a dissociated phenotype of resistance.

\section{Streptococci}

Among the streptococci, Str. pneumoniae and Str. pyogenes are the most frequently involved in respiratory and skin infections. Sixty-one of 62 strains of Str. pneumoniae appeared to be sensitive to achievable concentrations of the four macrolides, but one strain made an exception, exhibiting a quite resistant pattern. Here, the MICs were respectively $12.8 \mathrm{mg} / \mathrm{l}$ for roxithromycin, $6.4 \mathrm{mg} / \mathrm{l}$ for erythromycin, $3.2 \mathrm{mg} / \mathrm{l}$ for spiramycin and $0.4 \mathrm{mg} / \mathrm{l}$ for josamycin. All 38 strains of Str. pyogenes appeared to be susceptible to the four macrolides, with similar activities of the compounds on a weight basis. In the report by R. C. Spencer however, one erythromycin-resistant Str. pyogenes was also resistant to roxithromycin, and similar observations are reported in the literature (Jones et al., 1983; Barlam \& Neu, 1984).

\section{$H$. influenzae}

Roxithromycin and the three other macrolides showed consistent, although modest, antimicrobial activity against type b (14 strains) and non-type b (6 strains) $H$. influenzae. The results reported in this study regarding the specific activity of roxithromycin against $H$. influenzae are similar to the findings of Jones $e t$ al. (1983) and Jorgensen, Redding \& Howell (1986), but slightly less favourable than those reported by Barlam \& Neu (1984) or by Chantot, Bryskier \& Gasc (1986).

\section{Other bacteria}

C. Bebear, dealing with ten strains of $M$. pneumoniae, reports that MICs were $<0.01 \mathrm{mg} / 1$ for both erythromycin and roxithromycin in all cases. The report by K. Suzaki and Y. Niitu revealed that the strains resistant to erythromycin had a similar degree of resistance to roxithromycin.

According to J. Fleurette's report, the MIC $_{100}$ of different species of Legionella were as follows: $0.25 \mathrm{mg} / \mathrm{l}$ for roxithromycin, $0.5 \mathrm{mg} / 1$ for erythromycin and $1 \mathrm{mg} / \mathrm{l}$ for josamycin. This favourable activity was also reported by J. F. Acar, A. Buré and I. D. Farrell. Using her model of cell culture against $C$. psittaci, J. Orfila showed that roxithromycin had an activity (inhibition of bacterial growth) starting at a concentration of $0.5 \mathrm{mg} / \mathrm{l}$. This activity was shown after $24 \mathrm{~h}$ of contact, increasing after $48 \mathrm{~h}$ and $72 \mathrm{~h}$, and was comparable with that of erythromycin, josamycin, tetracycline and minocycline. R. C. Spencer showed that the $\mathrm{MIC}_{50}$ and $\mathrm{MIC}_{90}$ of 
erythromycin and roxithromycin against Pasteurella spp. were $4 \mathrm{mg} / \mathrm{l}$ for both drugs (range of MICs, $0.5-4 \mathrm{mg} / \mathrm{l}$ ).

In conclusion, macrolides such as erythromycin have a good activity against staphylococci, streptococci, some Haemophilus strains, Legionella spp. and C. psittaci and have been extremely useful in diseases caused by these organisms. They have been recommended for upper respiratory infections, such as otitis, sinusitis, or eradication of group A streptococci from the throat. Erythromycin is the standard therapy for $M$. pneumoniae and legionella pulmonary infection. Also, macrolides are indicated in mild respiratory or skin infections caused by streptococci or staphylococci, as an alternative to $\beta$-lactams in penicillin-allergic patients.

Roxithromycin, which shows antibacterial activity very similar to that of erythromycin, is reported to have more favourable pharmacokinetic properties than erythromycin. Roxithromycin could, therefore, be a useful antibiotic in selected skin and respiratory infections.

\section{Acknowledgements}

We express our gratitude to C. Bebear, K. Suzaki, Y. Niitu, J. Fleurette, I. D. Farrell, A. Buré, J. Acar, J. Orfila and R. C. Spencer for their generous permission for us to use some of their data for completion of this article.

\section{References}

Barlam, T. \& Neu, H. (1984). In vitro comparison of the activity of RU 28965, a new macrolide, with that of erythromycin against aerobic and anaerobic bacteria. Antimicrobial Agents and Chemotherapy 25, 529-31.

Chantot, J. F., Bryskier, A. \& Gasc, J. C. (1986). Antibacterial activity of roxithromycin: a laboratory evaluation. Journal of Antibiotics 39, 660-8.

Garrod, L. P. (1957). The erythromycin group of antibiotics. British Medical Journal ii, 57-63.

Jones, R. N., Barry, A. L. \& Thomsberry, C. (1983). In vitro evaluation of three new macrolide antimicrobial agents, RU 28965, and RU 29702, and comparisons with other orally administered drugs. Antimicrobial Agents and Chemotherapy 24, 209-15.

Jorgensen, J. H., Redding, J. S. \& Howell, W. (1986). In vitro activity of the new macrolide antibiotic roxithromycin (RU 28965) against clinical isolates of Haemophilus influenzae. Antimicrobial Agents and Chemotherapy 29, 921-2.

Lyon, B. R. \& Skurray, R. (1987). Antimicrobial resistance of Staphylococcus aureus: Genetic basis. Microbiological Reviews 51, 88-134.

National Committee for Clinical Laboratory Standards (1983). Methods for dilution antimicrobial susceptibility tests for bacteria that grow aerobically. Tentative Standard M7. T. National Committee for Clinical Standards, Villanova, Pa.

Rolston, K. V. I., LeBlanc \& Ho, D. H. In-vitro activity of Ru 28965, a new macrolide, compared to that of erythromycin. Journal of Antimicrobial Chemotherapy 17, 161-3.

Weisblum, B. (1985). Inducible resistance to macrolides, lincosamides and streptogramin type B antibiotics: the resistance phenotype, its biological diversity, and structural elements that regulate expression-a review. Journal of Antimicrobial Chemotherapy, 16, Suppl. A, 63-90. 
